\title{
Delitos de Posse e Ação Significativa - Crítica aos Besitzdelikte a partir da Concepção Significativa da Ação
}

\section{Possession Crimes and Meaningful Action - Criticism of Besitzdelikte from the Theory of Meaningful Action}

Paulo César Busato

Universidade Federal do Paraná, Curitiba - PR, Brasil

\begin{abstract}
Resumo: o presente trabalho se dispõe a discutir criticamente a fórmula dos delitos de posse a partir da teoria da ação significativa. Para isso, neste artigo, será descrito o desenvolvimento das teorias da ação no Direito penal do Civil Law e do Common Law para chegar ao ponto de conexão nas teses de Vives Antón e George Fletcher a respeito do conceito de ação.
\end{abstract}

Palavras-chave: Delitos de Posse. Teoria da Ação Significativa. Common Law, Civil Law. Vives Antón. George Fletcher.

\begin{abstract}
: this paper intent critically discuss the possession crimes formula, from the theory of meaningful action. To do so, describes the development of the action's theories in criminal law so the civil law as the common law to reach the connection point in the thesis of $\mathrm{Vi}$ ves Anton's and George Fletcher's concepts of action.

Keywords: Possession Crimes. Theory of Meaningful Action. Common Law. Civil Law. Vives Anton, George Fletcher.
\end{abstract}

\section{Introdução}

Uma das características mais marcantes do chamado moderno Direito penal tem sido o emprego de técnicas de tipificação que produzem adiantamento de barreiras de imputação, limitando, com isso, as possibilidades probatórias de defesa, com consequente recorte de Direitos individuais.

Recebido em: 09/11/2015

Revisado em: 1\%05/2016

Aprovado em: 02/05/2016 
Dentre essas técnicas, merece destaque a fórmula de delitos de posse (Besitzdelikte), que tem figurado em boa parte da recente legislação produzida no Brasil, e que é responsável por um considerável volume dos casos apreciados pelos juízos criminais.

O resultado é um claro processo de expansão do encarceramento, que pode ser demonstrado numericamente e que está evidentemente vinculado ao emprego dessas técnicas. Por outro lado, as fórmulas dogmáticas tradicionais pouco ou nada têm a oferecer em termos de rendimento crítico destas técnicas de tipificação, essencialmente porque as possibilidades críticas estão associadas à questão da $a c ̧ a ̃ o$.

As teorias do delito tradicionais, por sua ancoragem em conceitos ontológicos de ação, jamais produziram qualquer recorte da incriminação do ato de possuir.

Nas fórmulas funcionalistas, precisamente o desprezo pelo conceito de ação, tampouco pode produzir qualquer rendimento crítico a respeito do tema.

Diante deste quadro, o que o presente artigo pretende demonstrar é que a adoção de uma concepção significativa de ação, ancorada em bases linguísticas que arrancam dos estudos de Vives Antón e George Fletcher consegue oferecer sólida crítica aos delitos de posse desde um ponto de vista da própria exigência de ação, demonstrando que tais fórmulas incriminadoras violam o chamado act requirement, convertendo-se praticamente em incriminações de estados de pessoa.

É possível afirmar que uma concepção significativa de ação possui uma capacidade de rendimento crítico que não é alcançada pelas fórmulas tradicionais, consistindo um modelo mais desenvolvido, avançado, humanista e ajustado a um Direito penal mínimo.

\section{Técnicas de Tipificação como Instrumento de Expansão do Encarceramento Penal}

Não se pode afirmar com segurança, como já é comum na literatura jurídico-penal e criminológica desde o estudo de Silva Sánchez (1999), 
que efetivamente existe um processo de expansão do Direito penal, a partir da constatação simplória da existência de um número crescente de leis contendo normas incriminadoras.

A despeito de que as próprias bases em que se ancora o estudo mencionado sejam questionáveis (MARTÍNEZ-BUJÁN PÉREZ, 2014, p. 85-99), mais importante parece ser o reconhecimento de que a revolução cibernética e os outros avanços tecnológicos próprios do nosso tempo multiplicaram o número de relações sociais diárias que todos temos. Naturalmente, se há um aumento no número de relações sociais em geral, é certo que uma parte dessas mesmas relações será ilícita. Ou seja: um aumento no número de relações sociais que remetem à intervenção penal, por si só, não serve para demonstrar a existência de um processo de expansão do Direito penal simplesmente porque é natural que ele ocorra onde aumentam as relações sociais em geral.

Seria necessário buscar - e não se tem notícia da existência - para este fim, um estudo detalhado e comparativo sobre a proporção entre condutas lícitas e ilícitas antes e depois do avanço tecnológico-cibernético. Ou seja, para falar de expansão de Direito penal com base no número geral de incriminações existentes, seria preciso demonstrar que hoje, diferentemente do que antes, uma porcentagem maior do total de relações sociais são ilícitas.

No que aqui interessa especificamente, seria necessário demonstrar que no Brasil de hoje em dia dentro do total das relações sociais cotidianas teria havido um aumento proporcional de relações sociais ilícitas, em contraposição a um decréscimo das lícitas, o que não parece ter sido demonstrado.

Por outro lado, os dados do Instituto Brasileiro de Geografia e Estatística, quando cotejados com os dados do Departamento Penitenciário do Ministério da Justiça, oferecem a demonstração de uma efetiva expansão: a do encarceramento.

Segundo os órgãos mencionados, no ano de 1990, a população brasileira era de aproximadamente 143 milhões de habitantes. Destes, a população que se encontrava recolhida em cárceres era de aproximadamente 90 mil pessoas. 
No final de 2014, durante o último levantamento oficial do DEPEN, o número de encarcerados era de aproximadamente 550 mil pessoas. Em contrapartida, a estimativa do IBGE a respeito do fechamento do ano de 2015, em termos de população, é de que tenhamos um total aproximado de 204 milhões de pessoas.

Isso significa, claramente, que o aumento no número de encarcerados nos últimos 25 anos foi bastante superior ao aumento da população. Enquanto a população brasileira, de 1990 a 2014-2015, cresceu em torno de $33 \%$, a população carcerária cresceu em um número superior a $500 \%$.

A questão que se coloca, então, é que embora não seja possível afirmar que o número de relações sociais ilícitas tenha crescido em números proporcionais, é certo que cresceu muito o encarceramento.

Sendo assim, o foco de estudos deveria voltar-se, obviamente, para o que existe entre a realização das relações sociais e o encarceramento, ou seja, devemos ter atenção ao processo pelo qual aquilo que se faz (as condutas interpessoais) levam pessoas a serem presas.

Esse espaço é ocupado pelo processo de criminalização, no âmbito primário (criação das leis) e secundário (aplicação das leis aos casos concretos). Aí deve residir o foco de qualquer estudo sério sobre expansão em matéria penal.

O que aparece neste ponto é um mais do que evidente processo de avanço de barreiras de imputação através do emprego de técnicas de tipificação que promovem um adiantamento da conclusão pela imposição de uma pena, tais como delitos de perigo abstrato, bens jurídicos coletivos e espiritualizados, abuso da norma penal em branco e elementos normativos do tipo, delitos de violação de dever (Pflichtdelikte), delitos imprudentes e delitos de posse (Besitzdelikte).

Se todo delito se equilibra em um desvalor de ação e um desvalor de resultado, as técnicas de tipificação que encurtam exigências a respeito destes dois pólos, certamente podem corresponder a um real processo de expansão.

E é isso que se nota nos nossos dias. 
O avanço no âmbito do desvalor de resultado se traduz no aumento progressivo do emprego da técnica de delitos de perigo, em especial os de perigo abstrato, os delitos de violação de um dever (Pflichtdelikte) e a identificação de bens jurídicos coletivos.

Por outro lado, no que se refere ao desvalor de ação, há vários pontos no plano do processo de criminalização primária, como o abuso da norma penal em branco e dos elementos normativos do tipo e o incremento do número de figuras imprudentes. Mas no que se refere a um processo que envolve a criminalização primária e a secundária, a quebra da exigência de uma ação deriva na criminalização de um estado de pessoa traduzida na técnica dos delitos de posse.

Se com relação aos demais aspectos o foco da crítica pode ser dirigido ao legislador, no que refere aos delitos de posse, a própria hermenêutica aplicada ao processo de criminalização secundário permite um importante recorte.

Importa notar que a fórmulas de imputação dos delitos de posse não são propriamente inovadoras, já que a técnica se conhece desde o Direito romano, com a punibilidade da conduta de ambulare cum telo (Digesto, 48.8.3.1), ou a posse de veneno (SCHROEDER, 2004, p. 156), antecedente dos atuais delitos de posse ilegal de armas e drogas.

Acontece que é um fato inescapável que cada vez mais se recorre legislativamente a noções como a posse para definir o âmbito do punível (COX LEIXELARD, 2012, p. 6).

Schroeder refere uma expressiva moderação do emprego da técnica dos delitos de posse coincidente com o período da chamada Ilustração (SCHROEDER, 2004, p. 156). A retomada da proliferação de delitos de posse data, segundo a doutrina, da segunda metade do século $\mathrm{XX}^{1}$.

\footnotetext{
${ }^{1}$ Um dos casos mais perseguidos recentemente em todo o mundo é o caso da posse de material de pornografia infantil. O tem é comentado por Schroeder (SCHROEDER, 1993 , p. 2.581-2.582). Outro ponto característico do moderno direito penal é o delito de posse de meios destinados à neutralização de dispositivos protetores de programas de informática, artigo 270, parágrafo $3^{\circ}$ do Código penal espanhol. Também apontando para a retomada de importância dos delitos de posse (Eckstein, 2001, p. 22 e ss; NESTLER, 2000, p. 63 e ss.).
} 
Com isso, é possível estabelecer um paralelo entre os períodos de política criminal menos punitiva com o recorte das fórmulas de delito de posse, o que permite admitir que tal técnica constitui um importante instrumento repressivo.

Tanto é assim, que os autores que defendem a validade dos delitos de posse não duvidam em apontar que "[...] a penalização da posse serve para poupar a necessidade de prova da aquisição de objetos [...]" (SCHROEDER, 2004, p. 162), sustentando, porém, que tal circunstância não lhes retira a legitimação (SCHROEDER, 2004, p. 164).

Evitando, desde já, uma maior digressão acerca do tema (MENDOZA BUERGO, 2001; PRITTWITZ, 2002, p. 427 e ss), é possível afirmar que há consenso doutrinário sobre a existência atual de um avanço de barreiras de imputação e que um dos principais meios pelos quais tal avanço se manifesta e que tem despertado crescente interesse doutrinário, tem sido a técnica normativa de delitos de posse. Afirma-se que "[...] o recurso aos delitos de posse converteu-se em uma das estratégias prediletas do novo denominado Direito penal de risco ou de segurança" (COX LEIXELARD, 2012, p. 19).

A questão central nestes casos é que o ato de possuir não é, geralmente, em si mesmo, nocivo; nociva é a utilização do objeto que se possui, circunstância que precede o próprio ato de posse (MUÑOZ CONDE; CHIESA, 2009, p. 25).

O que se pode afirmar é que a punição de tais delitos não é mais que uma pretensão de reduzir o potencial de utilização de um objeto perigoso (MUÑOZ CONDE; CHIESA, 2009, p. 25).

Nessas situações, é questionável a existência de uma conduta. Aparece aqui algo muito próximo do que certa feita a doutrina alemã qualificou de Zustandsdelikte (delitos de estado) ${ }^{2}$, com o claro problema de que se pode perguntar, com respostas negativas, se o sujeito $f e z$ algo ou se o sujeito desejou cumprir um dever. A punição é de um estado de pessoa, e abre passo para um Direito penal de autor, adequado apenas na visão dos

\footnotetext{
${ }^{2}$ Sobre a relação entre delitos de posse e delitos de estado, ver em ECKSTEIN (2001, p. 227 e ss). Sobre o reconhecimento da posse como Besitzdelikt, ver em Ambos (2014, p. 24-25).
} 
herdeiros do discurso punitivo, que saem em defesa do emprego de fórmulas capazes de ampliar indevidamente o castigo ${ }^{3}$.

Por outro lado, convém fazer constar que esta situação político-criminal, coincide, ao menos nos principais sistemas jurídicos ocidentais, com um momento em que o conceito de ação se movimenta para uma posição de ostracismo nas fórmulas de imputação.

\section{O Rise and Fall da Ação em Direito Penal}

É possível detectar tanto no Direito continental quanto no chamado common law, uma parábola a respeito da discussão em torno da ação em matéria penal.

Tanto a ancoragem em um conceito ontológico de ação no âmbito do Direito continental teve um apogeu e uma superação, quanto o act requirement, como requisito para a incriminação no Common Law, passou por um momento de relevância e um progressivo descrédito.

\subsection{Evolução da Discussão sobre um Conceito de Ação na Dogmática Penal Continental}

No princípio das formulações de um conceito analítico de delito, a pretensão de dar ao próprio sistema de imputação um aspecto científico ${ }^{4}$, determinou que se adotassem, para a definição de delito, conceitos afirmados por outras ciências. A grande discussão se concentrava em torno da causalidade (GIMBERNAT ORDEIG, 1990, p. 169), que se apontava como o ponto chave da determinação do caráter científico do Direito penal.

\footnotetext{
${ }^{3}$ Por exemplo, Cox Leixelard, 2012, p. 69 e ss); quem trata de distorcer a teoria da ação de Vives, ao invés de defender a punição da posse com um discurso político criminal mais adequado a posições cegas aos efeitos da atuação do sistema de imputação como as de Jakobs ou mesmo Mezger.

${ }^{4}$ A pretensão era produto não só do impacto produzido no mundo por teses como a de Darwin, como também pela pretensão de dar uma resposta para a conhecida crítica de Kirchmann (KIRCHMANN, 1949, p. 29), em 1847, no sentido de que três palavras do legislador bastariam para converter bibliotecas inteiras em lixo.
} 
Entretanto, a excessiva amplitude do conceito ontológico de causa (conditio sine qua non) e a insuficiente capacidade de rendimento das teorias normativas (causalidade adequada, por exemplo), que negavam a causalidade em situações onde esta estava indubitavelmente presente, levaram a doutrina a se inclinar a favor do desenvolvimento do outro elemento do injusto - a ação - como o base da teoria do delito (GIMBERNAT ORDEIG, 1990, p. 169). E para que esta tivesse um perfil científico, tomava-se por referência o conceito de ação da física newtoniana (TOLEDO, 1994, p. 93).

Para von Lizst (1927), autor do tratado mais importante do final do Século XIX e início do Século XX, a ação consistia em uma modificação do mundo exterior, perceptível pelos sentidos, produzida por uma manifestação de vontade que se expressava na realização ou omissão de um movimento corporal voluntário. Para ele, "[...] a manifestação de vontade, o resultado e a relação de causalidade são os três elementos do conceito de ação" (LISZT, 1927, p. 297, 300 e 302).

Em um primeiro momento, os conceitos não se afastavam muito do eixo proposto por Lizst, por exemplo Beling (1944, p. 19).

O avanço dos modelos de sistemas de imputação, com a constante falência dos paradigmas (KUHN, 1987, p. 27) em um ou outro ponto, obrigou a reconstrução permanente do conceito de ação (LUZÓN PEÑA, 1993, p. 250).

Serve de exemplo a influência que teve o neokantismo, como perspectiva epistemológica axiológica na explicação de conceitos penais, entre eles, o conceito social de ação (TAVARES, 2009, p. 106; GUARAGNI, 2005, p. 104).

Isso se pode observar nos comentários feitos por Eberhard Schmidt (1969, p. 339) ao tratado do seu mestre von Liszt, com o objetivo de depurar o conceito causal proposto por aquele da excessiva influência das ciências naturais, ao definir a ação como "[...] conduta motivada pela vontade que adere, através de seus efeitos, à esfera da vida do próximo e se apresenta, sob aspectos normativos, como unidade de sentido social". 
O ponto de partida de Eberhard Schmidt foi compartilhado e desenvolvido por muitos outros autores como Wessels (1980, p. 20), Jescheck (1969, p. 149), Kienapfel (1966), Oehler (1951) e Wolff (1964), além de receber a adesão dos partidários do conceito objetivo-final da ação como Engisch (1965, p. 38 e ss) ou Maihofer (1971, p. 178).

O conceito geral de delito recebeu constantes e sucessivas reformulações, sempre tendo como base um conceito de ação, até encontrar o seu auge quando todo o sistema de imputação foi estruturado sobre ele.

Com o finalismo - concepção que se pretendia opor, tanto ao causalismo quanto ao neokantismo (WELZEL, 1977, p. 197) - se estabeleceu uma divisão que assumiu perfis de uma verdadeira guerra de escolas, que dominou a discussão no Direito penal do sistema jurídico continental como um todo, por volta de uns cinquenta anos (MUÑOZ CONDE; CHIESA, 2009, p. 9).

Não se pode esquecer que tal discussão foi impulsionada artificialmente por interesses de ordem político-criminal de algum autor, como bem colocado em destaque a conhecida pesquisa de Muñoz Conde (2001). Mas, não se apaga da história o protagonismo que o conceito de ação alcançou em termos de teoria do delito com a discussão entre causalistas e finalistas.

Por fim, em termos dogmáticos, era possível explicar, a partir de cada um destes conceitos de ação, sistemas de imputação completos e absolutamente diferentes um do outro.

Este tipo de discussão - assim como o protagonismo do conceito de ação em matéria penal - durou, no mínimo, mais do que duas décadas.

O início da perda de importância do conceito de ação em matéria penal coincide com o desenvolvimento das bases teóricas do funcionalismo.

Demonstrada a artificialidade da ideia dos vínculos ontológicos (ROXIN, 1998, p. 108), se trasladou, talvez indevidamente, as críticas válidas contra o ontologicismo para o próprio conceito de ação. 
No plano epistemológico o funcionalismo basicamente modificou a pergunta sobre o Direito penal, pois já não se tratava de discutir o que é o Direito penal, mas sim discutir para que ele serve.

Essa perspectiva teve a vantagem de se distanciar da pretensão de verdade latente em todos os modelos de imputação de base ontológica. Por outro lado, uma vez que o conceito de ação simbolizava a referida base, as construções funcionais da teoria do delito foram progressivamente abandonando as referências a este conceito, desvinculando-se, primeiramente, da base estrutural da teoria do delito, que começava não mais pela ação, mas sim pela imputação ou pela categoria da tipicidade, ou ainda, a própria ilicitude (BUSATO, 2007, p. 135).

A funcionalização do Direito penal traduziu, indubitavelmente, uma migração desde o campo ontológico para o axiológico em termos de base estrutural do sistema de atribuição de responsabilidade.

Este recorte implica, naturalmente, uma melhor visão do cenário político-criminal, deixando claro que a composição do sistema punitivo é, antes de mais nada uma escolha e, como tal, representa o modelo de Estado de onde deriva.

Contudo, o ponto mais agudo do funcionalismo conduz o eixo do debate penal para a norma, olvidando o componente humano que sempre esteve, de algum modo, atrelado à ideia de incluir na discussão aquilo que os homens fazem.

Não é um acaso que, a partir do funcionalismo se desenvolveu intenso debate sobre a estabilidade da norma como eixo do sistema de imputação; questionou-se a validade e capacidade de rendimento da teoria do bem jurídico como critério de limitação da intervenção penal; desenvolveu-se uma teoria da prevenção geral positiva como fundamento da pena e retomou-se a importância da teoria da impressão como fundamento da culpabilidade.

Ao lado de tudo isso, no plano das normas incriminadoras, apareceram com cada vez mais frequência o emprego de técnicas de tipificação que implicaram avanços de barreiras de imputação e, não poucas vezes, 
embora traduzidos em expressões verbais, disfarçavam um claro déficit de conduta, como por exemplo, os chamados delitos de posse.

Ao partir-se de uma redução da importância do conceito de ação na teoria do delito, a trilha estava aberta para construções não comprometidas com o controle de condutas, mas muito mais voltadas a um controle de comportamentos ou de estados pessoais.

\subsection{O Debate sobre o Act Requirement no Direito Penal Estadunidense}

Pode-se descrever um cenário político-criminal muito similar nos países do common law, em especial nos Estados Unidos da América, se considerada a discussão em torno do act requirement.

Desde o precedente Robinson vs. California ${ }^{5}$, quando a Suprema Corte estadunidense recusou a possibilidade de acusação contra o réu por "estar viciado no uso de narcóticos", com base na proibição de incriminação de estados de pessoas, convencionou-se, naquele espaço jurídico, que só seria possível incriminar alguém por uma conduta, ou seja, que existe a exigência de uma ação para determinar a possibilidade de atribuir-se responsabilidade criminal.

Assim, firmou-se, no âmbito jurídico dos Estados Unidos da América, como princípio jurídico penal, o act requirement.

Desde então, com distintas fórmulas, ganhou força esta conclusão na doutrina, que se afirmou como dominante, a ponto de que inclusive

\footnotetext{
${ }^{5}$ Lawrence Robinson foi abordado na rua em Los Angeles por um policial, que percebeu que os braços de Robinson estavam muito feridos, pálidos e cheios de marcas de agulhas. A polícia levou Robinson à prisão. No dia seguinte, um perito da divisão de narcóticos examinou seus braços e concluiu que as marcas e a palidez de seus braços eram resultado do uso de agulhas hipodérmicas não esterilizadas. Robinson admitiu o uso ocasional de entorpecentes e foi acusado de violar a lei da Califórnia que incriminava "o vício em uso de narcóticos". Ao contrário da maior parte das leis penais, que exigem que uma pessoa seja condenada somente por um acontecimento criminal, neste caso, Robinson poderia ser condenado pela sua condição, ou seu status de viciado em drogas. O Júri o condenou e o Tribunal recursal da Califórnia confirmou a condenação. A decisão foi reformada pela Suprema Corte Estadunidense com base na exigência de uma ação para incriminar.
} 
seus críticos reconhecem que "[...] virtualmente todos os livros e tratados respondem afirmativamente [...]" (HUSAK, 2011, p. 107) a tal exigência.

Inicialmente, houve coincidência em afirmar a ação em Direito penal desde um ponto de vista que coincidiu basicamente com as fórmulas causais mais elementares, tais como, a ideia do movimento corporal voluntário, que constava de escritos datados do século XIX (AUSTIN, 1869, p. 424 e ss).

A evolução da discussão sobre a exigência de uma ação como forma de incriminação nos Estados Unidos da América chegou ao seu ápice, tal como aconteceu no âmbito do direito continental, com a consagrada fórmula de Michael Moore, que põe o eixo da ação na intenção de realização, numa perspectiva muito similar às primeiras formulações de Welzel, vez que reconhece na voluntariedade que rege o movimento corporal, a expressão de estado mental de desejos e crenças.

Moore (1993, p. 133) afirma que "[...] existe um estado (ou conjunto disjuntivo de estados) que provoca o movimento motor, e é quase obviamente provável que tais estados sejam distintos quando o movimento motor é uma ação e quando não é”. Mas, logo acrescenta que o conteúdo de tal conjunto de estados que dispara o movimento motor da ação é um estado de volição que se deve discutir no mesmo nível em que se discute a existência de crenças, desejos e intenções.

Assim, trata as volições como os estados que são estudados desde os gregos como parte do senso comum da psicologia das pessoas racionais.

Como se nota, a similitude com a explicação de Welzel é mais que evidente (FLETCHER, 2007, p. 269-270), quando este afirma que “[...] é a vontade consciente do fim, que rege o acontecer causal, a coluna vertebral da ação final. Ela é o fator de direção que determina o acontecer causal exterior e em virtude disto o converte em uma ação dirigida finalmente" (WELZEL, 2003, p. 49).

O conteúdo da ação, assim como a explicação de uma intenção é o argumento comum entre Moore e Welzel a ponto de que a afirmação do professor alemão de que "[...] a vontade final pertence, por isso, à ação como fator integrante $[\ldots]$ já que configura o acontecer exterior [...]" 
(WELZEL, 2003, p. 49) poderia tranquilamente ser atribuído ao autor estadunidense.

Em Act and Crime, Michael Moore traduz o act requirement como "[...] um movimento corporal causado por uma intenção" (MOORE, 1993, p. 45). Às omissões, justifica o castigo a partir de um postulado de liberdade, limitando sua punibilidade a situações em que ao déficit de liberdade representado pelo castigo da omissão pode ser contraposto à injustiça de não castigá-la, com o que, somente em poucos casos se autorizaria o castigo das omissões (MOORE, 1993, p. 59).

Este ponto de vista foi muito bem recebido pela doutrina anglo-americana (PILLSBURY, 1996, p. 112; HURD, 1994, p. 157-184), não obstante sua evidente fragilidade no fundamento de castigo da omissão (MUÑOZ CONDE; CHIESA, 2009, p. 17-18). De fato, não há dúvida de que é o dever de solidariedade, especialmente relacionado com a condição das pessoas no contexto social do fato, o que determina a relevância da omissão de socorro, por exemplo, e não qualquer classe de discussão sobre a liberdade (MUÑOZ CONDE; CHIESA, 2009, p. 18).

Entretanto, depois de um amplo reconhecimento do act requirement em matéria jurídico-penal, recentemente tem se ampliado muito o número de autores que desprezam tal exigência, por diferentes motivos (DUFF, 2004, p. 69-103; SIMESTER, 1997; HUSAK, 2011, p. 107-123).

Merece especial destaque Douglas Husak (2011, p. 107), quem sustenta que "[...] a determinação de se a responsabilidade penal requer ou não uma ação não é de vital importância [...]" e afirma que aos filósofos do Direito penal tem importado mais a afirmação em si mesma que os efeitos substanciais de tal afirmação.

$\mathrm{O}$ autor sustenta que não foi difícil para o legislador da Califórnia, por exemplo, depois do caso Robinson, simplesmente converter a lei que tratava do vício, por uma proibição do uso de narcóticos, o que permitiu a continuidade da chamada war on drugs (HUSAK, 2011, p. 108).

Por isso, Husak (2011, p. 108) entende que o act requirement tem como única função prática a delimitação da imputação em um número 
muito limitado de situações em que igualmente escapa a culpabilidade e não se pode reconhecer, do mesmo modo, a intenção ou a negligência.

A isso acrescenta Husak (2011, p. 108) a crítica de não existir uma uniformidade a respeito do que é efetivamente a ação e, como consequência disso, não existir uniformidade sobre como o act requirement deve ser formulado.

Husak (2011, p. 109-110) apresenta os clássicos problemas de imputação nas hipóteses de omissão e as dificuldades de reconhecimento de uma ação ontológica - seja nas bases clássicas ou na fórmula de Moore - em casos limítrofes como o conhecido exemplo da guarda do Palácio de Buckinham, o qual, ainda que permaneça imóvel durante muito tempo, realiza a ação de vigiar.

Como proposição, Husak (2011, p. 108) migra para o campo normativo, apresentando, em substituição do critério do act requirement o que ele denomina de control principle.

A partir disso, Husak (2011, p. 114-115) sustenta não ser razoável fundamentar as punições a partir de que a situação castigada, embora não seja em si mesma uma ação, baseia-se em uma ação prévia ou futura a ela conectada, uma vez que, se assim for, seria possível legitimamente punir a alguém que pensasse em derrubar a Estátua da Liberdade em um ataque terrorista, já que esta é uma ideia que se baseia em uma ação. De tudo isso, tira a conclusão de que mais que o ato em si mesmo, o que sustenta a responsabilidade penal é o controle sobre uma situação.

Ou seja, o decisivo ao se punir tanto uma omissão quanto uma ação, não é a realização, mas a capacidade de controle que alguém exerce sobre a referida situação. Propõe, por fim, a substituição do act requirement, por um control requirement (HUSAK, 2011, p. 166 e ss).

Opõe a Moore especificamente, que o decisivo para o reconhecimento da responsabilidade penal não é a própria ação, nem sequer a escolha sobre atuar ou não (HUSAK, 2011, p. 118). Assim, para a punição de quem conduz um veículo sem ingerir a sua medicação contra a epilepsia ou do guarda do Palácio de Buckingham, o decisivo é o controle que possuem sobre a realização do que fazem ou deixam de fazer, assim como para o sonâmbulo ou aquele que reage ao inseto que lhe bate na face de- 
pois de entrar pela janela do carro, o que lhes retira a possibilidade de imputação é a perda do controle e não a falta de ação.

Sua conclusão, obviamente, traduz a questão para o plano exclusivamente normativo (HUSAK, 2011, p. 118 e 121), porque, sem dúvidas, a análise a respeito do controle é um juízo de valor que se faz sobre a capacidade de alguém de controlar determinada situação específica e os resultados dela derivados.

A crítica de Husak ao conceito de ação questiona diretamente a validade do conceito de ação como elemento principal da responsabilidade penal, chegando a afirmar que "[...] devemos parar de formar opiniões sobre a ação e, possivelmente, rechaçá-la por completo" (HUSAK, 1987, p. 97).

Husak (2011, p. 111-112) adota como campo de prova da sua explicação justamente os delitos de posse, onde sustenta que não existe uma ação propriamente dita.

Há, com efeito, um grande número de incriminações de delitos de posse nos Estados Unidos da América, tais como posse de drogas, armas de brinquedo, máquinas de clonagem de cartões de crédito, registro de empréstimos usurários, registros de apostas, material pornográfico, materiais poluentes e um longo etc..

O normativismo evidente na explicação de Husak remete a tratar o conceito de ação com o mesmo ceticismo manifestado alguma vez por Roxin, em sua crítica a Welzel, quando qualificou os conceitos de ação propostos pela doutrina causal e final como absolutamente imprestáveis fora do Direito penal e de pouca importância teórica e nula significação prática em si. Não reconhecia neste supraconceito sistemático outro valor que o puramente estético-arquitetônico (ROXIN, 1962, p. 515, 520).

\section{Um Passo à Frente a Respeito do Sistema de Imputação: o mo- delo fulcrado na linguagem}

A bipolaridade entre o ontológico e o normativo, entre o a excessiva importância e o completo desprezo a respeito da ação foi a tônica que marcou as construções jurídico-penais até muito recentemente. 
Entretanto, o Direito penal não poderia remanescer imune à aproximação que a Filosofia da Linguagem tem feito a todas as áreas do conhecimento humano.

Segundo Hassemer (1984, p. 221), essa aproximação progressiva entre o Direito e a linguagem advém justamente da necessidade daquele de produzir respostas a problemas práticos:

A classificação da semiótica - teoria da linguagem e de seu uso é muito útil, se se quer conhecer os limites nos quais a lei pode vincular o juiz. Na "sintaxe" ou sintática trata-se das relações dos sinais linguísticos entre si, de gramática, de lógica, de forma e de estruturas. Na semântica, trata-se das relações dos sinais linguísticos com a realidade, de significado, de experiência, de realidade. $\mathrm{Na}$ pragmática se trata da relação dos sinais linguísticos com o seu uso em situações concretas, de ação, de comunicação, de retórica, de narração.

Um novo referencial para o desenvolvimento desta pretensão se oferece a partir da Filosofia da linguagem. As teorias da argumentação e da comunicação têm possibilitado uma mudança de ponto de vista desde as aspirações do próprio direito, no sentido de, por um lado, mudar a pretensão de verdade por uma pretensão de justiça e, de outro, permitir a confluência de aspectos normativos e ontológicos pela medida da comunicação de um sentido.

Essa posição, porque inovadora, naturalmente conta com adesão ainda tímida, embora nitidamente crescente, no cenário jurídico penal do civil law - por exemplo: Vives Antón (1996); Martínez-Buján Pérez (2012); Orts Berenguer; González Cussac (2004); Borja Jiménez (1999, p. 117 e ss); Cuerda Arnau (2009); Carbonell Matteu (2004, p. 139 e ss); Gorriz Royo (2008); Ramos Vázquez (2008). No Brasil, assumindo expressamente a dimensão da linguagem na elaboração da teoria do delito Busato (2007); Mascarenhas Júnior (2009) e Porciúncula (2014). Adotando o modelo comunicativo de um conceito de ação, Tavares (2009, p. 200 e ss). De um modo mais superficial, Queiroz (2008, p. 9).

Há, sem dúvida, algum fator que lhe explica. 
A dogmática penal tem sido, para a Alemanha, um produto de exportação de muito êxito, mas, tem sido vendido como um produto dotado de uma precisão que, em realidade, simplesmente não existe.

Pela primeira vez na história da dogmática jurídico-penal, a proposição de um novo paradigma epistemológico para a teoria do delito não nasce na Alemanha.

A ampla difusão do pensamento jurídico e filosófico alemão em todo o mundo e a escassa atenção dedicada pelos autores alemães para o que acontece nos outros âmbitos jurídicos associada à velocidade das informações nos dias de hoje, terminou por deslocar o lugar de desenvolvimento dos avanços na área dos sistemas de imputação.

É possível afirmar que o estudo das bases filosóficas que remontam a Wittgenstein, inspiraram autores, tanto no plano do direito continental quanto do common law, no que se refere à reforma da estrutura do sistema de imputação, a partir de tais fundamentos epistemológicos, em especial no que refere ao conceito de ação.

Assim, pode-se dizer que existe uma coincidência no sentido de que a falência dos conceitos ontológicos de ação, tanto no civil law como no common law, produziu um déficit de contenção do sistema punitivo representado pelas tendências funcionalistas, que fez com que emergisse, em ambos os cenários jurídicos, concepções que guardam estreita proximidade.

No plano do direito continental, trata-se dos estudos oferecidos pelo Prof. Vives Antón, os quais puseram em relevo que a partir da filosofia da linguagem é possível oferecer uma nova aproximação a respeito da ação, já não sob forma de conceito, referido a uma definição, mas sim sob forma de concepção, atrelada à sua compreensão contextual que pode, perfeitamente, constituir uma das bases para a estruturação do sistema de imputação.

Essa ideia encontra-se espelhada na obra do Professor de Columbia George Patrick Fletcher, cujas conexões com a ideia de ação trabalhada por Vives Antón são mais que evidentes e, inclusive, foram admitidas expressamente pelo primeiro (FLETCHER, 2007, p. 281-282). 
Embora vinculado a uma forma de trabalho bastante mais pragmática - e logo, mais simples - que o monumental livro de fundamentos do Prof. Vives, Fletcher oferece um conceito intersubjetivo de ação que, por um lado, pretende superar o modelo ontológico que orientou sempre os estudos jurídico-penais estadunidenses e, por outro, estabelece uma base estrutural para o próprio sistema de imputação (MUÑOZ CONDE; CHIESA, 2009, p. 13) que não despreza uma concepção de ação e com isso, supera os funcionalismos de qualquer vertente.

Assim como a teoria de Vives, as proposições de Fletcher não são dominantes no âmbito jurídico do common law, embora nitidamente recebam cada vez mais atenção dos penalistas.

Importa destacar, portanto, as coincidências das explicações de Fletcher e Vives a respeito da teoria da ação, em especial o papel central que tal conceito de ação ocupa em suas estruturações.

\subsection{A Importância da Concepção de Ação no Sistema de Vives Antón}

Vives parte da concepção fundamental de que a ação não poder ser um fato específico e nem tampouco ser definida como o substrato da imputação jurídico-penal, mas que representa "um processo simbólico regido por normas" (VIVES ANTÓN, 1996, p. 205) que vem a traduzir "o significado social da conduta" (VIVES ANTÓN, 1996, p. 205). Assim, para Vives a concepção de ação é a seguinte: “[...] interpretações que, segundo os distintos grupos de regras sociais, podem ser dadas ao comportamento humano [...]" (VIVES ANTÓN, 1996, p. 205) e, portanto, elas deverão representar, em termos de estrutura do delito, não o substrato de um sentido, mas o sentido de um substrato (VIVES ANTÓN, 1996, p. 205).

Com isso, Vives consegue diferenciar entre ações - que são dotadas de sentidos ou significados (VIVES ANTÓN, 1996, p. 208-211) e comportam interpretações - e fatos - que não têm sentido e comportam tão somente descrições.

Por outro lado, o sentido de tais ações é ditado por regras que as regem (VIVES ANTÓN, 1996, p. 213). 
Essas regras, contudo, se reconhecem como tais enquanto tenham seu uso estabelecido, pois, somente assim podem determinar o sentido de uma conduta. Portanto, elas não podem ser reduzidas unicamente ao padrão de regras jurídico-positivas ou legais, como alguma vez se fez (JAKOBS, 1997, p. 865 e ss.; COX LEIXELARD, 2012, p. 95), em contraposição rudemente distorcida da compreensão comunicativa original (HABERMAS, 1987, p. 127-129 e 137-138). Ou seja, o reconhecimento da ação deriva da expressão de sentido que uma ação possui em sua praxis, em seu uso. A expressão de sentido, contudo, não advém das intenções que os sujeitos que atuam pretendam expressar, mas do "[...] significado que socialmente se atribua ao que fazem" (VIVES ANTÓN, 1996, p. 214). Assim, não é o fim mas o significado que determina a classe das ações, logo, ação não é algo que se defina em termos ontológicos, mas sim que se reconhece em termos normativos. Vives deixa claro com um exemplo:

[...] minha compreensão de uma partida de futebol depende de conhecer as regas do jogo e, de que, por conseguinte, possa efetuar uma correta atribuição de intenções aos movimentos dos jogadores: se desconheço as regras, não sou capaz de inferi-las e ninguém me explica, não entenderei o jogo e não saberei, na realidade, o que está acontecendo ali (nem ao menos poderei adivinhar o que pretende fazer um jogador que está na posse da bola). Mas, uma vez que as conheço e posso fazer, por conseguinte, as atribuições de intenção corretas, nem sempre avaliarei as jogadas (as ações dos jogadores) baseado nas pretensões que eu lhes atribuo: v.g., se um defensor tem a intenção de limpar a área, mas coloca a bola na sua meta, não direi que ele limpou a área, mas que marcou um gol contra sua própria equipe. As atribuições de intenção são, como eu disse, baseadas no seguimento de regras e são construtivas do significado, em termos gerais, mas não na forma de uma relação um a um: as regras, que materializam em atribuições de intenção, operam, frequentemente, apartadas do propósito de quem as segue ou as infringe. (VIVES ANTÓN, 1996, p. 215)

A ação é determinada pelo sentido que lhe dão as regras segundo as quais é interpretada. Por isso, “[...] a determinação da ação que se realiza 
não depende da concreta intenção que o sujeito queira realizar, mas do código social conforme o que interpreta o que foi feito." (VIVES ANTÓN, 1996, p. 216).

As práticas sociais são então, contingentes da ação e da intenção (VIVES ANTÓN, 1996, p. 218). Se fala de intenções já expressas nas ações e não determinantes delas. Por isso, “[...] os movimentos corporais não são interpretados como ações por causa da presença prévia ou contemporânea de intenções [...]" (VIVES ANTÓN, 1996, p. 218), na verdade, é a existência de um seguimento de regras que permite identificar o sentido que se faz na ação e aferir a realização de uma intenção (VIVES ANTÓN, 1996, p. 218). Logo, “[...] há uma intencionalidade externa, objetiva, uma prática social constituinte do significado." (VIVES ANTÓN, 1996, p. 219).

Além disso, é também certo que nem toda ação é intencional (VIVES ANTÓN, 1996, p. 215-216), o que outra vez comprova que o núcleo da ação não está na intencionalidade, o que explica claramente o fracasso do modelo finalista proposto por Welzel em explicar o delito imprudente.

Ao contrário, a proposta de Vives de seguir o modelo filosófico de Wittgenstein, se afasta de tudo isso para identificar a ação segundo o significado, as regras e o seguimento das regras.

Assim, por um lado, reconhece-se que há uma relação interna entre ação e intenção, mas isso de modo algum determina que toda a ação, como expressão de sentido, deva consistir, necessariamente, expressão de uma intenção (VIVES ANTÓN, 1996, p. 223).

Resulta pois que, em termos normativos, existem tanto ilícitos imprudentes quanto dolosos, sendo que o que identifica estes últimos - por certo - normativamente, é a expressão de sentido que se traduz no compromisso com a produção do resultado típico, que não ocorre na imprudência.

É necessário, finalmente, deixar claro que o elemento fundamental que orienta o esquema de Vives e que, ao mesmo tempo lhe insere a dimensão de preservação do componente humano - ainda que normativamente estruturado - é a ideia de liberdade de ação, que é justamente o ponto de união entre a sua teoria da ação e sua teoria da norma (os dois pilares básicos do seu sistema de imputação). 
Para Vives, a ideia de que a liberdade de ação situa-se na culpabilidade tem provocado um intenso e aporético debate entre o determinismo e a vontade livre, conduzindo a um beco sem saída.

Assim, propõe Vives algo completamente diferente: que a liberdade de ação não fundamente a culpabilidade, mas sim a própria ação. A liberdade de ação tem que ser o pressuposto da imagem de mundo que dá sentido à própria ação (MARTÍNEZ-BUJÁN PÉREZ, 2014, p. 62 e ss).

Isto é, não se comprova a liberdade de ação com base empírica, mas se trata de conceber o mundo desde a liberdade de ação nela mesma expressada, que é o que permite o juízo de aplicabilidade de alguma norma. Ao contrário, se reconhecida a ausência de tal liberdade, não se pode pretender aplicação de nenhuma classe de regulamentação jurídica (COBO DEL ROSAL; VIVES ANTÓN, 1999, p. 542-543).

Após o longo percurso que Vives empreende, tanto na sua análise da doutrina penal quanto da filosofia sobre a ação, o autor aponta para a importância da adoção de uma adequada concepção de ação em matéria jurídico-penal.

Esta não reside em dar resposta às perguntas que a doutrina tradicionalmente vem apresentando a partir de diferentes conceitos explicativos de ação. Ao contrário, o que se propõe é justamente mudar a própria pergunta.

Ou seja, a proposição de entender a ação como um sentido oferece o ponto de vista adequado para perceber que o problema do supraconceito de ação estava, na verdade, mal apresentado, devendo dissolver-se como problema, para deixar revelar o que estava por baixo, que é a autêntica essência dos problemas relacionados com a ação em matéria jurídico-penal (VIVES ANTÓN, 1996, p. 206).

Entre eles, saltam como evidentes recortes minimalistas às perguntas sobre o que é e como se produz o significado, e o que é uma intenção e quando podemos atribuir intenções (VIVES ANTÓN, 1996, p. 222).

Com isso, é mais que evidente que, partindo de outro referencial epistemológico, se renova, na discussão sobre a imputação, a necessidade de demonstração da ação como elemento chave da mesma imputação. 
Depois de intensa crítica metodológica e de funcionalidade às fórmulas ontológicas (causalistas e finalistas) e aos modelos de imputação funcionalistas, que sobrecarregaram aspectos relacionados à relevância da ação, à lesividade da ação e também à contrariedade do dever, Vives propõe a reconstrução da teoria do delito a partir da categoria do tipo de ação (VIVES ANTÓN, 1996, p. 273).

A análise que faz, nesta categoria, da ação em si mesma, tem o objetivo de reconhecer "[...] se, efetivamente, estamos ou não diante de uma ação de uma classe que se trate ou, inclusive, se podemos ou não falar de ação - qualquer que seja a classe de ação em que pensamos" (VIVES ANTÓN, 1996, p. 260). Ou seja, se

[...] nos achamos diante de uma ação (isto é, diante de uma conduta que segue uma regra e que, por conseguinte, pode ser entendida como uma ação enquanto incorpora um significado) e não perante um simples fato da natureza. (VIVES ANTÓN, 1996, p. 276)

Com esse quadro é possível afirmar que a partir da concepção de Vives, entra em franca evidência, outra vez, a discussão a respeito da ação, para fins de afirmação da responsabilidade penal.

\subsection{O Papel Central do Requisito da Ação (act requirement) no Sistema de Imputação de George Fletcher}

No seu livro Basic Concepts in Criminal Law, Fletcher inicia a discussão sobre a ação em Direito penal com a afirmação sobre uma concordância entre todos os sistemas jurídicos: que a pena só pode ser imposta em decorrência de uma ação humana (FLETCHER, 1998, p. 44).

Este é um ponto de intersecção indubitável. Seja um sistema jurídico baseado na teoria do delito, seja um sistema jurídico baseado em precedentes judiciais, a pena é uma resposta a condutas.

Outra coisa, muito diferente, é a definição do que é, efetivamente, ação e efeitos penais. 
Para discuti-lo, Fletcher adota um método de recorte negativo, ou seja, procura atacar as respostas à pergunta sobre a ação que considera insuficientes.

Em primeiro lugar, como é óbvio, rechaça a ideia de ação como movimento corporal (FLETCHER, 1998, p. 44). Aponta como razão mais forte para ele, o fato de que "[...] se A pega a mão de $B$ e golpeia a C, a mão de B certamente se moveu, mas, isso não constitui uma ação" (FLETCHER, 1998, p. 44). Em sua exposição, admitir isso como ação equivaleria a tratar o autor como objeto e não como sujeito (FLETCHER, 1998, p. 44).

Com efeito, o ato de imputar a responsabilidade penal não pode ser uma imposição contra alguém pelo simples movimento, porque este pode ser o resultado de uma intervenção alheia. Castigar por simples movimento implica reconhecer na mesma fórmula do castigo uma espécie de imposição que não trata seu destinatário como um sujeito capaz de interferir na possibilidade de aplicação da norma a partir de suas decisões, senão como mero objeto de intervenção estatal.

Em seguida, Fletcher aponta que, de maneira geral, a condição de sujeito, que determina a ação, ou seja, de sujeito que é "dono e senhor" de determinada conduta, geralmente se associa à vontade.

Ou seja: para que um movimento corporal possa ser identificado como ação, é preciso vinculá-lo à vontade de um autor.

O problema é que disso derivou uma opinião, mais ou menos estendida, tanto no Direito estadunidense, quanto no Direito europeu continental, de que a ação seria uma contração muscular voluntária (HOLMES JR., 1881), movimento corporal voluntário (FLETCHER, 1998, p. 44).

Fletcher, contudo, adverte que conceber a ideia de que a ação, em termos penais, como um movimento voluntário, conduz a diferentes problemas, um deles de aspecto filosófico: “[...] como saber quando o movimento da mão é consequência de uma vontade de mover a mão?" (FLETCHER, 1998, p. 45).

A par disso, é bastante óbvio que a falta deste mesmo movimento voluntário nem sempre pode representar a ausência de uma ação, como se 
poderia pensar a respeito do psiquiatra que utiliza o silêncio como terapia ou os estudantes que escutam calados as explicações do professor ou da pessoa que, maquiada e fantasiada, permanece imóvel em uma praça, ao lado de um chapéu com uma placa pedindo por doações (FLETCHER, 2007, p. 271-272). Em nenhum destes casos, é possível falar que o sujeito não realizou uma ação.

Por outro lado, o mesmo psiquiatra, se dormiu durante a sessão, não poderá dizer que fez terapia (FLETCHER, 2007, p. 272).

O professor estadunidense aponta que esta constatação conduz a um ciclo vicioso, pois, “[...] definimos a ação como manifestação de vontade, mas sabemos que a vontade é operacional somente se percebemos a ação no movimento corporal do autor." (FLETCHER, 1998, p. 45).

Assim parece evidente que não é possível basear a identificação da ação nem no simples movimento voluntário, nem na simples vontade interna do sujeito. Há algo mais que conduz a reconhecer em uma situação concreta que um sujeito realiza como obra sua e por isso, deve ser responsável pelos resultados que dela derivam.

Esse ponto é esclarecido de melhor forma mais tarde, por Fletcher, no seu Grammar of Criminal Law, ao propor que é "[...] a noção de discurso e de significado comunicativo do discurso que nos oferece, pois, uma tomada adequada da teoria da ação.” (FLETCHER, 2007, p. 279).

O ponto fundamental de onde se deve estudar a ação é que se trata de um conceito que deve ser fixado no futuro e por terceiros, com o qual está longe de poder ser estabelecido a partir de uma abstração metafísica separada do seu contexto e da realidade social na qual os sujeitos atuam.

O decisivo é, pois, “[...] a forma que nós, como observadores, compreendemos se o movimento ou o não movimento constituem uma ação." (FLETCHER, 2007, p. 282).

No que se refere ao conceito de omissão, igualmente Fletcher faz um recorte negativo, começando por criticar, como inadequada, a ideia de que "[...] se não faço as coisas, as estou omitindo" (FLETCHER, 1998, p. 46). No mínimo, não é possível pensar a imputação penal a partir dis- 
so, já que nem tudo o que deixamos de fazer se pode considerar omissão (FLETCHER, 1998, p. 46).

$\mathrm{O}$ autor utiliza os exemplos de dar uma esmola a um mendigo não significa a omissão de dá-la a outros quantos mendigos e o exemplo do médico que, ao atender um paciente não está omitindo o tratamento a milhares de outros (FLETCHER, 1998, p. 45).

Conclui Fletcher (1998, p. 46) que o omitir depende de fatores contextuais que convertem o fazer omitido como uma conduta esperada e normal.

Em seu Grammar of Criminal Law o autor finalmente desenvolve de modo mais vertical uma concepção comunicativa de ação com base justamente na ideia de que a ação se determina segundo o contexto no qual um movimento ou um não-movimento tem lugar. Ou seja: para determinar se a ação é de tal relevância que a torna passível de traduzir responsabilidade penal, é necessário examinar as circunstâncias nas quais determinada conduta comissiva ou omissiva tem lugar.

Em resumo: para Fletcher (2007, p. 282), os atos não devem ser entendidos como um processo ontológico puro nem como orientação de desejos internos, mas como uma forma de comunicação, como uma conduta significativa que tem sentido tanto para a pessoa que atua quanto para todos nós.

Assim, a compreensão da ação/omissão como algo que deriva de um contexto, conduz a levar em conta, eventualmente, os vários atos realizados como elementos contextuais componentes da própria ação, de tal modo que não se pode - como geralmente ocorre com os modelos de matriz ontológica - confundi-la com os atos fracionários que a compõem (MUÑOZ CONDE; CHIESA, 2009, p. 12).

\subsection{O Papel Central da Concepção de Ação de Fletcher em seu Sistema de Imputação}

Fletcher (2007, p. 266), assim como Vives, refere-se expressamente à importância da discussão a respeito do conceito de ação em Direito pe- 
nal, que se traduz em proibir o emprego do aparato punitivo contra outras coisas que não sejam condutas.

E é a partir da comunicação que se estabelece as notas distintivas da ação, porque só ela é capaz de uma abordagem compreensiva e não meramente explicativa do fenômeno da ação (FLETCHER, 2007, p. 281).

Fletcher (2007, p. 286) acrescenta que:

Na hora de estruturar a definição do delito, a noção de ação humana constitui a base de uma série de distinções básicas em Direito penal. As ações contrastam com as ações voluntárias, com culpabilidade, com consequências e com status. E mais, a distinção entre o Direito penal baseado na ação e o Direito penal baseado na pessoa do delinquente se converteu em uma questão central da atual política criminal.

Não há dúvida alguma, portanto, que os dois autores que fundam seus conceitos de ação na filosofia da linguagem estão de acordo em que a ação exerce um papel decisivo no sistema de imputação.

\section{A Insustentável Condição da Posse como Ação na Matriz Significativa-Comunicativa}

Acontece que essas perspectivas a respeito da ação, em seu caráter comunicativo de significado do que se faz, resulta incompatível com a ideia de posse.

É mais evidente que ainda que se possa afirmar que possuir é um verbo, que seria identificado em um modelo finalista, por exemplo, com um fazer, alguém que está na posse de qualquer objeto, pelo simples fato de estar na posse, não realiza - ao menos em sentido comunicativo - uma ação.

Tanto é assim que, o próprio Model Penal Code quando determinou a legitimação dos delitos de posse o admitiu apenas “[...] se o possuidor conscientemente ganhou ou recebeu a coisa possuída e estava consciente de seu controle em relação a ela durante um período suficiente para ter sido capaz de rescindir sua posse". Ou seja: a posse é passível de casti- 
go não pelo simples possuir, senão por outras condutas precedentes ou descumprimento de deveres subsequentes. Note-se que a justificação da incriminação da posse se baseia não sobre a posse em si, mas sobre o fato da obtenção ou recebimento da coisa e no dever de dela se livrar, que são, respectivamente, ação e omissão.

É evidente que se a ação deve ser identificada a partir de um contexto social compartilhado, convoca-se as teorias sociais para dentro da teoria jurídica da imputação e com base no uso social será determinada a relevância social de determinada ação (MUÑOZ CONDE; CHIESA, 2009, p. 13).

Assim, tanto a classe de arma utilizada para agredir importa para a determinação de uma pretensão de causar a morte ou somente lesões, como a situação financeira de um empresário que desvia dinheiro para sua empresa pode ajudar a diferenciar um erro de registro de uma fraude (MUÑOZ CONDE; CHIESA, 2009, p. 13).

Portanto, é possível afirmar, com Fletcher (2007, p. 281), que “[...] a noção de comunicação pela linguagem permite uma aproximação humanística ao conceito de ação".

Desde o plano político-criminal, a recuperação do protagonismo da teoria da ação no âmbito da teoria do delito permite estruturar a crítica a partir da sua função que é justamente vincular o controle social penal a condutas, facilitando a discussão a respeito da legitimidade de técnicas de tipificação que colocam em suspeita a expressão de um Direito penal do fato, em especial a mais que discutível técnica dos chamados delitos de posse (Besitzdelikte).

Eis um ponto chave no qual a retomada da discussão a respeito da ação desde um viés linguístico prova cabalmente possuir um inigualável potencial crítico, com o que supera definitiva e insofismavelmente, por um lado, a insuficiência da desesperada migração axiológica das correntes funcionalistas e, por outro, a renitência e o apego tradicionalista a inúteis concepções ontológicas a respeito da ação em matéria penal, proveniente, em nosso país, principalmente do ranço finalista. 
Segundo Fletcher, o caso Robinson - já referido - é um bom exemplo de castigo de estado de pessoa, uma vez que o Estado da Califórnia o condenou por ser um viciado. Fletcher critica este e todos os casos de delito de posse a partir da ideia que se trata de delitos de uma amplitude excessiva, uma vez que "[...] nem todo aquele que possui realiza uma conduta que ameaça a outros ou que é, em um sentido significativo, perigosa [...]", constituindo verdadeiro exemplo de malum prohibitum (FLETCHER, 2007, p. 295).

Essa categoria de imputação é notadamente uma das formas mais evidentes de expansão do Direito penal, no sentido nocivo que pode guardar o termo (LAGODNY, 1996, p. 318 e ss).

Por isso, o resgate da importância da discussão a respeito da ação constitui um mecanismo legítimo, humanista e democrático de resistência contra o avanço punitivo.

Como bem destacam Muñoz Conde e Luís Chiesa, se a ação é o centro gravitacional da imputação, dela são recortados fatores extrínsecos ao ato, como a periculosidade do autor, seu pertencimento a determinado grupo étnico ou racial, suas convicções políticas ou religiosas, etc. (MUÑOZ CONDE; CHIESA, 2009, p. 7), enfim, todas as tendências abusivas da incriminação de estados de pessoa. Esta questão funda todas as fórmulas de estruturação da teoria do delito, porém, nem os modelos clássicos (causalista ou finalista), nem as fórmulas axiológicas (funcionalistas), foram capazes de gerar qualquer capacidade de rendimento crítico frente aos delitos de posse.

Mas uma concepção de ação adequadamente desenvolvida pela via da linguagem e ocupante de uma posição de protagonista no sistema de imputação pode permitir negar legitimidade a esta classe de técnica de tipificação, evitando os recortes de garantias defensivas.

As ações são realizações de alguém e são diferentes dos fatos, porque estes simplesmente acontecem.

Examinemos mais de perto um exemplo: dois policiais descobrem em uma gaveta na casa de Daniel, um revólver. Perguntam-lhe pela licença para a posse da arma e Daniel diz que não a tem. Há delito de posse ilegal de armas? 
Suponhamos aqui duas variáveis probatórias. Na primeira, se demonstra que Daniel recebeu o revólver de Ricardo e ele mesmo guardou a arma na gaveta. Na segunda, Ricardo, quando esteve na casa de Daniel, colocou o revólver na gaveta e se esqueceu dele.

Parece lógico sustentar que somente no primeiro caso há delito.

Mas, por quê?

Não poderíamos dizer que a diferença para a existência da ação de possuir está em que no primeiro caso Daniel está consciente de que possui a arma e no segundo não, porque, neste caso, estaríamos sustentando a existência da ação na instância interna do sujeito, que é sua consciência, voltando à confusão entre o aspecto interno do querer e conhecer e o externo do reconhecer o que se realiza, ou seja, estaríamos pretendendo utilizar intenções para definir a ação.

Há que se reconhecer que o que faz diferença é que, na primeira variante probatória, Daniel recebeu a arma e o receber é uma ação. $\mathrm{Na}$ segunda, sua posse não deriva da sua condição de senhor e dono do fato, mas de uma postura de passividade, de algo que lhe aconteceu.

Claro está que se há omissão, a punição possível se vincula a um dever. Se Daniel estava consciente de que Ricardo deixara a arma na gaveta, deveria entrega-la às autoridades públicas. Mas, neste caso, igualmente, não é o fato de possuir o que se castiga, mas a violação do dever de entregar o revólver às autoridades. $\mathrm{O}$ dever de livrar-se da arma, uma vez que não tinha autorização para estar com ela (SCHROEDER, 2004, p. 167).

Com isso, chega-se a que as razões de reconhecimento da possibilidade de punição da posse ou derivam da ação precedente de receber ou da omissão subsequente do dever de entregar a arma, e nunca da posse dela.

E, por quê?

Porque a posse, em si mesma, é um fato e não uma ação (STRUENSEE; JAKOBS, 1998, p. 123-124), como já havia apontado o Model Penal Code estadunidense, referindo que a justificação do castigo não está em possuir, mas em adquirir e não se livrar da coisa adquirida, sendo possível fazê-lo. 
Desde o ponto de vista da dogmática alemã, sustenta-se a punibilidade da posse rechaçando o argumento do Model Penal Code a partir da afirmação de que "[...] os perigos não consistem na aquisição de objetos nem na omissão de sua entrega, mas na posse como estado." (SCHROEDER, 2004, p. 167).

Porém, esta posição não pode prevalecer porque o perigo abstrato de uma conduta, ou seja, um delito de conduta perigosa pode exprimir-se na conduta de adquirir ou na omissão da entrega, mas, nunca, na posse em si mesma. Assim, o tema não é definir o que é ou não perigoso mas $o$ que se pode proibir como conduta perigosa.

Ademais, a simples afirmação de que o perigo está em possuir é absolutamente falsa para uma grande quantidade de delitos, se levarmos em conta o bem jurídico. Por exemplo, a posse de pornografia infantil não amplia em nada a agressão ao bem jurídico intimidade que se lesionou pela aquisição e poderá ter ampliada sua lesão pela difusão, mas, nunca pela posse (ESQUINAS VALVERDE, 2006, p. 171-228, especialmente, p. 185 e ss).

Assim, o argumento do perigo resulta insustentável.

Do mesmo modo que possuir, brilhar ou valer também representa um fato em forma verbal. A diferença específica é que possuir supõe uma pessoa. Mas, isso não basta para converter um fato em ação. É que possuir, como brilhar ou valer, é algo que simplesmente ocorre a alguém ou a algum objeto. Mesmo que se trate de alguém, este alguém estará em uma condição de passividade e nunca como o dono e senhor da realização de algo.

Assim, conclui-se que possuir, em si mesmo, não pode ser ação, ainda que possa, isso sim, ser um elemento circunstancial probatório de uma $a c ̧ \tilde{a} o$ precedente ou de uma omissão subsequente.

\section{Conclusão}

O moderno Direito penal, especialmente no Brasil, contempla freqüente emprego de técnicas de tipificação que adiantam barreiras de imputação, entre elas a fórmula de delitos de posse (Besitzdelikte), promovendo um processo de expansão do encarceramento que precisa ser contido. 
Esta contenção pode ser feita não apenas recortando-se a incriminação em geral, mas também e principalmente dentro do próprio sistema de imputação através da adoção de novos paradigmas capazes de renovar o sentido crítico de recorte da intervenção penal em pontos onde as fórmulas dogmáticas tradicionais já não tem nada a oferecer. Entre essas possibilidades, figura, com destaque, a superação das teorias do delito tradicionais, por sua ancoragem em uma concepção significativa de ação. Esta fórmula, baseada nas concepções de Vives Antón e George Fletcher, consegue oferecer sólida crítica aos delitos de posse desde um ponto de vista da própria exigência de ação (act requirement), identificando hipóteses de incriminações de estados de pessoa, totalmente insustentáveis.

Como visto, somente a partir de uma compreensão da linguagem é possível avaliar corretamente os delitos de posse.

Por isso, recomenda-se não só o incremento dos estudos sobre a teoria significativa da ação, mas também, o esclarecimento e crítica a suas manipulações indevidas.

Verifica-se que as instruções jurídico-penais têm evoluído de tal maneira que se produziu uma natural aproximação entre os modelos do civil law e do common law. Nesta aproximação, um papel central é ocupado pelas contribuições da filosofia da linguagem, em especial a teoria da ação.

Essa teoria da ação significativa-comunicativa resulta um importante instrumento de recorte crítico frente a certos avanços indevidos de barreiras de imputação, por exemplo, aos delitos de posse, oferecendo um ganho de rendimento do qual tanto as teorias clássicas (causalista e finalista) quanto as modernas vertentes funcionalistas provaram-se incapazes.

Finalmente, não se pode esquecer que alguns novos objetos de atenção como a responsabilidade penal das pessoas jurídicas, as formas de participação delitiva e os níveis de reprovação subjetiva por práticas delitivas têm obrigado tanto aos teóricos do civil law como aos do common law a olhar para fora de seus próprios sistemas jurídicos, buscando no outro, soluções e a filosofia da linguagem, como base epistemológica, figura como importante eixo de aproximação ente os distintos sistemas ju- 
rídicos, o que é bem demonstrado pela aproximação dos autores referidos neste trabalho, a respeito de um tema tão essencial quanto a concepção jurídico-penal de ação.

Não é um acaso que o avanço de estudos como os de Ottfried Höffe caminham no sentido de desenvolvimento de um sistema penal intercultural (HÖFFE, 2008, p. 149 e ss). A aproximação entre os grandes sistemas jurídicos está na ordem do dia e a intersecção reside, principalmente, em uma epistemologia linguística, pois a linguagem estrutura a forma de existir do direito. Mais ainda, em direito penal, quando se trata de uma estrutura de atribuição de responsabilidade.

\section{Referências}

AMBOS, Kai. Posse como delito e a função do elemento subjetivo reflexões a partir de uma perspectiva comparada. Revista Portuguesa de Ciência Criminal, Coimbra, Coimbra Editora, ano 24, n. 1, janeiromarço, 2014.

AUSTIN, John. The Philosophy of positive law. 3. ed. London: John Murray, 1869.

BELING, Ernst. Esquema de Derecho penal: la doctrina del delito-tipo. Tradução de Sebastián Soler. Buenos Aires: Depalma, 1944.

BORJA JIMÉNEZ, Emiliano. Algunas reflexiones sobre el objeto, el sistema y la función ideológica del Derecho penal. Nuevo Foro Penal, [S.l.], n. 62, 1999.

BUSATO, Paulo César. Derecho penal y acción significativa. Valencia: Tirant lo Blanch, 2007.

CARBONELL MATTEU, Juan Carlos. Sobre tipicidad e imputación: reflexiones básicas en torno a la imputación del dolo e imprudencia. In: MATEU, Juan Carlos Carbonell et al. (Coord.). Estudios penales en recuerdo del Prof. Ruiz Antón. Valencia: Tirant lo Blanch, 2004. COBO DEL ROSAL, Manuel; VIVES ANTÓN, Tomás Salvador. Derecho Penal. 5. ed. Tirant lo Blanch: Valencia, 1999. 
COX LEIXELARD, Juan Pablo. Delitos de posesión: bases para una dogmática. Buenos Aires - Montevideo: BdeF, 2012.

CUERDA ARNAU, María Luísa. Límites constitucionales de la comisión por omisión.. In: MATEU, Juan Carlos Carbonell et al. (Coord.).

Constitución, derechos fundamentales y sistema penal (semblanzas y estudios con motivo del setenta aniversario del profesor Tomás Salvador Vives Antón). Valencia: Tirant lo Blanch, 2009. p. 415-436.

DUFF, Antony. Action, the Act Requirement and Criminal Liability. Royal Institute of Philosophy Supplement, [S.l.], v. 55, septiembre del 2004.

ECKSTEIN, Ken. Besitz als Straftat. Berlin: Dunker \& Humblot, 2001. ENGISCH, Karl. Vom Weltbild des Juristen. Heidelberg: Carl Winter Universitätsverlag, 1965.

ESQUINAS VALVERDE, Patricia. El tipo de mera posesión de pornografía infantil en el Código Penal Español (art. 189.2): razones para su destipificación. Revista de Derecho Penal y Criminología, Madrid: UNED, n. 18, 2 Época, 2006.

FLETCHER, George Patrick. Basic Concepts in Criminal Law. New York: Oxford University Press, 1998.

FLETCHER, George. The Grammar Of Criminal Law. New York: Oxford University Press, 2007.

GIMBERNAT ORDEIG, Enrique. Estudios de Derecho penal. 3. ed. Madrid: Tecnos, 1990.

GORRIZ ROYO, Elena. El concepto de autor em Derecho Penal. Valencia: Tirant lo Blanch, 2008.

GUARAGNI, Fábio André. As teorias da conduta em Direito penal. São Paulo: Revista dos Tribunais, 2005.

HABERMAS, Jurgen. Teoría de la acción comunicativa. Tradução de Manuel Jiménez Redondo, Madrid: Taurus, 1987. v. I,

HASSEMER, Winfried. Fundamentos del Derecho penal. Tradução de Francisco Muñoz Conde y Luís Arroyo Zapatero, Barcelona: Bosch, 1984. 
HÖFFE, Otfried. Derecho intercultural. Tradução de Rafael Sevilla, Barcelona: Gedisa, 2008.

HOLMES JR., Oliver Wendel. The Common Law. Boston: Little Brown, 1881.

HURD, Heidi M. What In the World Is Wrong? Journal of

Contemporary Legal Issues, Newcastle, v. 5, 1994.

HUSAK, Douglas. The Alleged Act Requirement in Criminal Law. In: DEIGH, John; DOLINKO, David. (Ed.). The Oxford Handbook of Philosophy of Criminal Law. New York: Oxford University Press, 2011.

HUSAK, Douglas. Philosophy of Criminal Law. Totowa: Rowman \& Littlefield, 1987.

JAKOBS, Günther. Derecho penal: Parte General. 2. ed. Corregida, tradução de Joaquín Cuello Contreras y José Luis Serrano Gonzales de Murillo. Madrid: Marcial Pons, 1997.

JESCHECK, Hans-Heinrich. Lehrbuch des Strafrechts. Berlin: Duncker \& Humblot, 1969.

KIENAPFEL, Diethelm. Das erlaubte Risiko im Strafrecht: zur Lehre vom sozialen Handlungsbegriff. Frankfurt a.M.: Klostermann, 1966.

KIRCHMANN, Julius Hermann von. La Jurisprudencia no es ciencia. Tradução de Antonio Truyol y Serra. Madrid: Instituto de Estudios Políticos, 1949.

KUHN, Thomas. La estructura de las revoluciones científicas. 1. ed. 12. reimp. Tradução de Agustín Contin. Madrid: Fondo de Cultura Económica, 1987.

\section{LAGODNY, Otto. Strafrecht vor den Schranken der}

Grundrechte: die Ermächtigung zum strafrechtlichen Vorwurf im Lichte der Grundrechtsdogmatik dargestellt am Beispiel der Vorfeldkriminalisierung. Tübingen: J. C. B. Mohr, 1996.

LISZT, Franz von. Tratado de Derecho Penal: tomo 2. 3. ed. Tradução de Luís Jiménez de Asúa. Madrid: Instituto Editorial Reus S.A., 1927. 
LUZÓN PEÑA, Diego-Manuel. Derecho penal: parte general I. Madrid: Editorial Universitas S.A., 1996.

MAIHOFER, Werner. Der soziale Handslungbegriff. In: SCHMIDT, Festschrift. Eberhard. Göttingen: Vandenhoeck \& Ruprecht, 1971. p. 156-182.

MARTÍNEZ-BUJÁN PÉREZ, Carlos. Derecho penal económico y de la empresa: parte general. 4. ed. Valencia: Tirant lo Blanch, 2014.

MASCARENHAS JÚNIOR, Walter Arnaud. Ensaio Crítico sobre a ação. Porto Alegre: Nuria Fabris, 2009.

MENDOZA BUERGO, Blanca. EI derecho penal en la sociedad del riesgo. Madrid: Civitas, 2001.

MOORE, Michael. Act and Crime: the philosophy of action and its implications for criminal law. New York: Oxford University Press, 1993.

MUÑOZ CONDE, Francisco; CHIESA, Luís Ernesto. A exigência de ação (act requirement) como um conceito básico em Direito penal. Revista Justiça e Sistema Criminal, Curitiba: FAE, n. 1. Tradução de Rodrigo Jacob Cavagnari e Paulo César Busato, 2009.

MUÑOZ CONDE, Francisco. Edmund Mezger y el Derecho penal de su tempo: los orígenes ideológicos de la polémica entre causalismo y finalismo. 2. ed. Valencia: Tirant lo Blanch, 2001.

NESTLER, Cornelius. La protección de bienes jurídicos y la punibilidad de la posesión de armas de fuego y de sustancias estupefacientes.

In: INSTITUTO de Ciencias Criminales de Frankfurt a.M. (Ed.). La insostenible situación del Derecho penal Tradução de Guilhermo Benlloch Petit. Granada: Comares, 2000. p. 65-74.

OEHLER, Dietrich. Der rechtswidrige Vorsatz. Juristenzeitung. Tübingen: Mohr Siebeck, 1951. p. 63-78.

ORTS BERENGUER, Enrique; GONZÁLEZ CUSSAC, Jose Luiz.

Compendio de Derecho penal: parte general y parte especial. Valencia: Tirant lo Blanch, 2004. 
PILLSBURY, Samuel H. Crimes of indifference. Rutger's Law Review, Newark: Rutger's School of Law, v. 105, 1996.

PORCIÚNCULA, José Carlos. Lo objetivo y lo subjetivo en el tipo penal: Hacia la exteriorización de lo interno. Barcelona: Atelier, 2014.

PRITTWITZ, Cornelius. El derecho penal alemán, ¿fragmentario? ¿subsidiario? ¿ultima ratio? Reflexiones sobre la razón y los límites de los principios limitadores del Derecho penal. In: INSTITUTO de Ciencias Criminales de Frankfurt a.M. (Ed.). La insostenible situación del Derecho penal. Tradução de Castiñeira. Granada: Comares, 2002. p. 427-446.

QUEIROZ, Paulo. Direito penal: parte geral. 4. ed. Rio de Janeiro: Lumen Juris, 2008.

RAMOS VÁZQUEZ, José Antonio. Concepción significativa de la acción y teoría jurídica del delito. Valencia: Tirant lo Blanch, 2008.

ROXIN, Claus. Contribuição para a crítica da teoria finalista da ação. Problemas Fundamentais de Direito penal. Trad. de Ana Paula dos Santos Luís Natscheradetz. 3. ed. Lisboa: Vega, 1998. p. 91-143.

SCHMIDT, Eberhart. Soziale Handlungslehre. In: ENGISH, Karl. Festschrift für, Frankfurt: Vittorio Klostermann, 1969.

SCHROEDER, Friedrich-Christian. Das 27. Strafrechtänderungsgesetz Kinderpornographie. Neue Juristische Wochenschrift, München: C. H. Beck, n. 40, 1993.

SCHROEDER, Friedrich-Christian. La posesión como hecho punible. Revista de Derecho penal y Criminología. Madrid: UNED, n. 14, 2. época, 2004.

SIMESTER, A. P. On the So-Called Requirement for Voluntary Action. Buffalo Criminal Law Review 403, [S.l.], v. 2, n. 1, 1997. SILVA SÁNCHEZ, Jesús-María. La expansión del Derecho penal: aspectos de la política criminal en las sociedades postindustriales. Montevideo-Buenos Aires: BdeF, 2006. 
STRUENSEE, Eberhard; JAKOBS, Günther. Delitos de tenencia, Problemas capitales del Derecho penal moderno. Tradução de Marcelo Sancinetti, Buenos Aires: Hammurabi, 1998. p. 107-124.

TAVARES, Juarez. Teoria do crime culposo. 3. ed. Rio de Janeiro: Lumen Juris, 2009.

TOLEDO, Francisco de Assis. Princípios Básicos de Direito Penal. São Paulo: Saraiva, 1994.

VIVES ANTÓN, Tomás Salvador. Fundamentos del sistema penal. Valencia: Tirant lo Blanch, 1996.

WELZEL, Hans. Derecho penal alemán. Tradução de Juan Bustos Ramírez y Sergio Yáñez Pérez. 11. ed. Santiago: Editorial Jurídica de Chile, 2003.

WELZEL, Hans. Introducción a la filosofía del Derecho: derecho natural y Justicia material. Tradução de Felipe González Vicén. Madrid: Aguilar, 1977.

WELZEL, Hans. O novo sistema jurídico-penal. São Paulo: Revista dos Tribunais, 2001.

WESSELS, Johannes. Derecho penal: parte general. Tradução de Conrado A. Finzi. Buenos Aires: Depalma, 1980.

WOLFF, Ernst Amadeus. Der Handlungsbegriff in der Lehre vom Verbrechen. Heidelberg: Carl Winter Universitätsverlag, 1964.

Paulo César Busato é doutor em Direito penal pela Universidad Pablo de Olavide (Sevilha, Espanha), professor adjunto de Direito Penal da Universidade Federal do Paraná e Procurador de Justiça do Ministério Público do Estado do Paraná. E-mail: pbusato2013@gmail.com.

Endereço profissional: Universidade Federal do Paraná, Praça Santos Andrade, n. $50-1^{\circ}$ andar, Centro, Curitiba, PR. Brasil. CEP: 88020-300. 
